\title{
DIE GEHEIM VAN DIE PREDIKING: OM MONDIG TE WORD ${ }^{1}$
}

\author{
J. Cilliers ${ }^{2}$ \\ ABSTRACT \\ THE SECRET OF PREACHING: FINDING YOUR \\ VOICE ON THE PULPIT
}

This article contends that preaching is a speech-act in which the voice of the preacher - symbol of his or her personality and spirituality - has an important role to play. It argues that the voice of the preacher is a factor not to be overlooked in the dynamic structure of communication, and should be cultivated in a theologically responsible manner. The function of the voice of the preacher should, however, not be understood as a new, homiletical moralism, but in its relationship to (a) the salvation works of God, (b) the relational integrity of the preacher, (c) the integration of prayer within the framework of the preacher's theology, and (d) a life of virtue before God. The main thrust of the argument is that preaching is constituted simultaneously by a deeply human and profoundly divine activity in the life of the church.

\section{OPSOMMING}

Hierdie artikel gaan uit van die oortuiging dat prediking 'n spraakgebeure is waarin die stem van die prediker - simbool van sy of haar persoonlikheid en spiritualiteit 'n belangrike rol het om te speel. Die stem van die prediker mag nie misken word in die dinamiese struktuur van kommunikasie nie, en moet inteendeel op 'n teologiesverantwoorde wyse gekultiveer word. Hierdie rol van die stem van die prediker mag egter nie verstaan word as 'n nuwe homiletiese moralisme nie, maar in relasie tot (a) die verlossingswerke van God, (b) die verhoudingsintegriteit van die prediker, (c) die integrasie van gebed binne die raamwerk van die prediker se teologie, en (d) die deugdelike bestaan voor God. Die kern van die artikel rus op die veronderstelling dat prediking uit beide 'n waarlik menslike én Goddelike handeling bestaan.

1 Uitbreiding van 'n referaat gelewer by 'n Buvton-byeenkoms oor Liturgie en Prediking, Stellenbosch 13 Augustus 2001.

2 Dr. Johan Cilliers, Departement Praktiese Teologie en Missiologie, Fakulteit Teologie, Universiteit van Stellenbosch. 


\section{INLEIDING}

"Die evangelie moet nie geskryf word nie, maar uitgeroep word... die kerk is nie 'n pen-huis nie, maar 'n mond-huis". Met hierdie uitspraak beklemtoon Luther die feit dat die prediking 'n bepaalde orale onmiddellikheid en dringendheid het; dat dit 'n persoon (Persoon!)-tot-persoon gebeure op 'n bestemde tyd en plek is (vgl. Meuser 1969:19, 30). God se Woord is primêr 'n gesproke Woord, maar dan as daad-gebeure, as daad-kragtige dabar. Sentraal in hierdie Doenwoord staan die Persoon van God, maar ook die persoon van die prediker. Prediking wat dít nie verstaan en in aanmerking neem nie, bring die wesenlike van die Woord in gedrang.

Stel jouself voor 'n prediker is na 'n week se worsteling met die teks gereed om te preek, maar word ongesteld net voor die diens. Hy of sy sou die uitgeskrewe preek kon laat sirkuleer en elke gemeentelid sou dit in stilte kon deurlees, of $\mathrm{n}$ voorganger sou dit namens die prediker kon doen. So 'n gesimuleerde voordrag, oftewel stem-in-absentia is immers nie 'n onbekende gebruik by sommige politieke en ander byeenkomste nie. Dit kán moontlik van betekenis vir sommige wees, maar in die erediens kan dit tog nooit die ware Jakob vervang nie. Die afwesigheid van die stem, en dus van die persoon van die prediker, skaad die wese van die prediking as 'n persoonlike, en dus menslike uitdrukking en verwoording van die Stem van God.

Die prediker sou uiteraard 'n kassetopname van sy of haar stem kon stuur, of 'n video-opname, of nog beter: per telefoon of satelliet-televisie met die gemeente kon praat. In die toekoms sal predikers dalk "teenwoordig" kan wees deur middel van 'n drie-dimensionele hologram! Goed en wel, maar tóg ontbreek iets, ontbreek dít wat tot die wese van die prediking hoort, naamlik die persoonlike en dinamiese oog-tot-oog-kontak, die lewende kommunikasie wanneer prediker en gemeente mekaar op 'n spesifieke tyd en plek in die teenwoordigheid van God in die erediens ontmoet. Inderdaad: die evangelie moet in die preek deur die mond van 'n mens uitgeroep word (vgl. Wilson 1995:47).

Die probleem is egter: hierdie "mond van 'n mens" kan in die prediking eerder 'n muilband as 'n ruimte vir God se mond en stem wees. Die persoon van die prediker, wat uiteraard ook sy of haar spiritualiteit betrek, kan 'n hindernis wees vir die spreke van God. In hierdie artikel word gevra na die teologiese mondigheid van predikers, en die teologiese basis van hulle spiritualiteit. Dit sluit vrae in soos: In watter mate word 'n teologiese begronding vir predikers se spiritualiteit in (enkele klassieke en resente) homiletiese denkpatrone as wesenlike onderdeel van die preekmaakproses beskou? Wat is die kenmerke van sodanige spiritualiteit? Wat verhinder of bevorder dit?, ensovoorts. 
Die vraag na die rol van die prediker in die preekmaakproses is natuurlik nie nuut nie. Trouens, daar sou 'n saak daarvoor uitgemaak kon word dat baie van ons homiletiese uitgangspunte in dié verband teruggevoer kan word na Aristoteles, wat die rol van die etos van 'n spreker as selfs meer grondliggend as logos en patos in die kommunikasieproses geskat het. Hy was van mening - teen die stroom van sy tyd in - dat die etos van 'n spreker belangriker is as die blote bemeestering van retoriese tegnieke.

In die kommunikatiewe homiletiek van byvoorbeeld Cas Vos duik hierdie klem op die etos weer op, as hy die klassieke retoriese differensiasie volg waarin beurtelings gelet word op die hoorders (wat oortuig moet word), die Bybelse teks (die waarheid wat ter sprake is) en die preek "uit die mond van die prediker" (dit wil sê 'n spreker wat outentiek moet oorkom; 1995: veral hoofstukke 6 en 7; ook Den Dulk 1995:8). Dis duidelik dat die persoon van die prediker vir Vos 'n integrale deel van die homiletiese proses uitmaak.

So ook by Hennie Pieterse - wat in sy hermeneutiese benadering tot die Praktiese Teologie en prediking sterk beïnvloed is deur Gadamer en Ricoeur. Pieterse kan beswaarlik oor die preekmaakproses skryf sonder om grondig te verwyl by die deurslaggewende "self-verstaan" van die prediker as prediker (2002:91; ook breedvoerig in 1988:62-72). Ook vir hom bly dit een van die onmisbare sleutels in die totale hermeneutiese en kommunikatiewe proses van preekmaak.

Daar is tans ' $n$ hernude belangstelling in die rol van die persoon van die prediker. In 'n resente studie van Malan Nel word byvoorbeeld indringend op hierdie saak ingegaan. Nel vind sterk aansluiting by belangrike empiriese navorsing wat deur $\mathrm{H}$. van der Geest in die laat sewentigerjare gedoen is, en werk temas soos opregtheid, egtheid, veiligheid (vertroue), gesag en verantwoordelikheid, asook gesonde self-openbaring grondig uit (2001:4569; ook 2000:112-135).

Dat hierdie beklemtoning nie sonder slaggate is nie, is net so waar. Die teologiese integrasie van stemme in die prediking (van prediker, teks, gemeente en God), kan hier maklik uitmekaar val. Jy kan onder die indruk kom dat álles afhang van jou persoonlikheid, of van die graad van jou spiritualiteit. Dit kan 'n nuwe vorm van moralisme word. Tog neem dit niks weg van die feit dat dit 'n verwaarloosde aspek in die (veral vertekende gereformeerde) homiletiek is wat aandag vra nie.

In hierdie artikel sluit ek aan by bogenoemde uitgangspunte, en vra ek veral na die spesifieke teologiese karakter van dié etos wat pas by die prediking. Die uitgangspunt is dus die oortuiging dat prediking 'n spraakgebeure is 
waarin die stem van die prediker - simbool van sy of haar persoonlikheid en spiritualiteit — 'n belangrike rol het om te speel. Die stem van die prediker mag nie misken word in die dinamiese struktuur van kommunikasie nie, en moet inteendeel op 'n teologies-verantwoorde wyse gekultiveer word. Hierdie rol van die stem van die prediker mag egter nie verstaan word as ' $n$ nuwe homiletiese moralisme nie, maar in relasie tot (a) die verlossingswerke van God, (b) die verhoudingsintegriteit van die prediker, (c) die integrasie van gebed binne die raamwerk van die prediker se teologie, en (d) die deugdelike bestaan voor God. Die kern van die artikel rus op die veronderstelling dat prediking uit beide 'n waarlik menslike én Goddelike handeling bestaan.

\section{DIE GEHEIM VAN DIE PREDIKING: OM MONDIG TE WORD}

\subsection{Die ek in diens van die Ek}

'n Belangrike stem wat gehoor word op die kansel, is dus die stem van die prediker self - en ek bedoel daarmee nie net sy of haar fisieke stem nie; eerder die totale menswees, eerder die teenwoordigheid van die prediker as persoon. Hierdie empiriese werklikheid kan tog nooit oor die hoof gesien word nie: wie op die kansel staan, is 'n mens van vlees en bloed, met 'n eie geskiedenis, 'n eie verhaal en 'n eie worsteling met God. Trouens, wie op die kansel probeer om enigiets ánders as haar- of homself te wees, maak ook van die prediking iets anders as wat dit veronderstel is om te wees. Op die kansel staan nie in die eerste plek 'n retoriese reus of 'n beskeie boodskapper of 'n betowerende verhaalverteller nie, maar 'n mens soos sy en hy wérklik is - coram deo, voor God. Dalk is daar te veel klone op ons kansels, eerder as oorspronklike skeppings. Dalk is daar te veel aangeleerde maniërismes, wat van geen mens 'n prediker kan mak nie. Met apologie aan alle predikers: elke voël moet sing soos hy (of sy) gebek is. As jy ánders wil sing as wat jy gebek is, is jy vals - in meer as een opsig van die woord.

Hierin sit daar altyd 'n soort spanning: die prediker staan nooit in die prediking op die voorgrond nie, mag tog nooit die hooffiguur in die drama van die preekgebeure word nie, maar is eerder een wat saam met die gemeente luister na wat God sê — als hoorder onder de hoorders, soos die bekende boek van Dingemanns (1991) getitel is. En tog is dit jy wat voor die gemeente staan, met jou kennis van die gemeente, jou teologiese insigte, jou eie persoonlikheid, beperkinge en potensiaal — en nie bloot 'n bandmasjien wat jou stem meganies in die ore van die gemeente laat opklink nie. 
In die prediking word die waarheid letterlik deur die menswees van die prediker beliggaam: "Authentic preachers are those who embody the Gospel they proclaim in their manner of delivery” (Ward 1992:129). 'n Mens dink ook aan die bekende uitspraak van Phillips Brooks: "Preaching is communicating divine truth through human personality" (1964:5).

In die prediking handel dit (onder andere) oor Ek... en ek. Elke preek staan of val met die groot Ek van God, met sy "Ek is wat Ek is" (Eks. 3:14), wat uitmond in "Ek is die brood van die lewe" (Joh. 6:35); "Ek is die lig vir die wêreld" (Joh. 8:12); "Ek is die goeie Herder" (Joh. 10:14); "Ek is die ware wynstok" (Joh. 15:1), ens. Hiervan hang alles af: dat hierdie Ek van God telkens weer in elke preek ter sprake kom en sigbaar word. Elke preek word deel van die geskiedenis en die toekoms van die groot Ek - of dit is geen preek nie. In diens van hierdie groot Ek staan die klein ek van die prediker. Die klein ek op die kansel is sélf 'n soort preek, is sélf 'n boodskap, of jy nou daarvan bewus is of nie.

Die realiteit is egter dat die klein ek dikwels nie 'n medewerker van die groot Ek is nie, maar 'n konkurrent; dat die klein ek 'n lang skaduwee oor die groot Ek gooi, en Hom in die preek verduister. Dikwels kondig die klein ek - bewus of onbewus - alreeds in die eerste sin van die preek sy of haar verhouding tot die groot Ek aan. Dikwels word die teologie, of gebrek daaraan, alreeds in die eerste sin van die preek gekonsentreer. Dikwels word die klok van die evangelie al klaar dáár gelui óf stilgemaak, word die prediker tot 'n beliggaming van die evangelie òf 'n wet wat moralisties op die hoorders inwerk. In plaas daarvan dat die klein ek minder word, en die groot Ek meer, vind die teenoorgestelde plaas (vgl. Joh. 3:30; ook Bohren 1988:98-107).

Predikers benodig, soos alle gelowiges, die daaglikse, voortgaande bekering — ook weg van hulle eie ydelheid af. Hulle moet weet: my "sukses" is nie noodwendig gelykstaande aan die evangelie nie. Die gevaar is groot dat predikers juis as gevolg van hulle amp of teologiese kennis of bedieningsukses tevrede kan rak met surrogate vir ware bekering, dat hulle so "gewoond" kan raak aan heilige dinge, dat hulle afstomp daarvoor en klinies daarmee begin omgaan. Jy kan die (jou) sonde begin rasionaliseer, in plaas daarvan om tot 'n goeie selfkennis te kom. Jy kan die fyn balans tussen selfverloëning en selfbevestiging misverstaan, en so al prekende self verwerplik word (vgl. 1 Kor. 9:27).

Om 'n prediker te wees, is daarenteen om volwasse nederig te wees, dit wil sê om teologies mondig te word. Hierdie mondigwording is, soos die bekering, 'n voortdurende proses, 'n toename in teologiese onderskeidingsvermoë en dus wysheid. Daarom mag predikers nooit "klaar" wees met hulle 
teologiese opleiding nie. Dis eerder 'n lewenswyse, 'n daaglikse ingroei in die wysheid. Een van die belangrikste vrae wat trouens van 'n predikant gevra kán word, is: is hy of sy wys? En, hand aan hand daarmee: is hy of sy werklik 'n teoloog? As predikers sê — soos hulle dikwels doen — "ek is nie eintlik 'n teoloog nie", verstaan hulle waarskynlik nie wat die woord teoloog beteken nie, en sou dit waarskynlik ook vir die prediking beter gewees het as hulle nie op die kansel gekom het nie. Wysheid en teologie het niks met hoogmoed of met "sukses" in die gebruiklike sin van die woord te make nie, maar met mondigheid, en daarom met nederigheid.

Nederigheid beteken egter weer nie 'n onderskatting van jou rol in die prediking nie. Wanneer die Gees werk, skakel Hy ons nie uit nie, maar in. Hy werk op 'n teonome resiproke wyse, behou die inisiatief, maar neem ons telkens in diens van die verkondiging van die evangelie. Wat vir óns onmoontlik is, maak Hy moontlik; wat vir ons onmaakbaar is, verander $\mathrm{Hy}$ in die maakbare (Bohren 1971:76-77). So verkry ons menslike bydrae in die prediking 'n bepaalde waarde, 'n spesifieke gesag.

Ons begrip van gesag is waarskynlik deur karikature daarvan gekontamineer. Die gesag van die prediker lê nie in outokrasie, veral nie geestelike of kerklike outokrasie of burokrasie nie. Ons gesag lê in gebrokenheid; ons bemagtiging in ontmagtiging. Grondliggend vir al ons pogings om tussengangers tussen die teks en die konteks te wees, is 'n hermeneutiek van die kruis. Wie hiérdie hermeneutiek nie verstaan nie, wie nie weet dat jy sterk is as jy swak is nie (2 Kor. 12:10), begryp nog nie die hartklop van die prediking nie. Ons gesag lê immers daarin dat ons nie kán nie, maar omdat God in ons werk, kán ons. Dit lê in die boodskap wat ons verkondig: die kruisdood en opstanding van Jesus Christus (vgl. Paulus se uitsprake in 1 Kor. 1:18-2:16). Maar die wonder is: dis óns wat dit verkondig! Waarlik, 'n mens kan nie anders as om dit dialekties te bely nie: dis die evangelie van Christus wat deur sy Gees in die wêreld verkondig word, maar dis ook óns wat ons monde oopmaak om daaroor te preek (vgl. Hand. 1:8)!

Dis $j y$ wat op die kansel as prediker staan, en daarvoor hoef jy nie verskoning te vra nie. Dis $j y$ met jou gawes, jou roeping, jou unieke verwoording van die evangelie. ' $n$ Mens dink onwillekeurig aan die epiese verhaal van Bart Nel, wat na 'n veelbewoë geskiedenis waarin hy feitlik alles wat vir hom dierbaar was, verloor het, aan die einde as 'n soort klimaks uitroep: "Ek is Bart Nel van toe af, en ek is nog hy" (Van Melle 1968:180). Daar sit inderdaad 'n stuk bevryding daarin om jouself te mag wees, veral ook op die kansel. Predikers het nodig om hierdie vryheid telkens te ontdek en te hérontdek — ter wille van die verkondiging van die evangelie. 


\subsection{Die (verhoudings)integriteit van die prediker}

Prediking is nooit 'n onbetrokke oordrag van kennis nie, maar 'n woord wat gebore word uit jou omgang met God, uit jou ontmoeting met God in die teks (Iwand 1964:19). Op geen manier mag jy wegkruip vir die gemeente nie, nie agter jou korrekte eksegese, of jou vinnige oplossings of jou verbysterende diepsinnighede nie. Op geen manier mag jou rol en jou masker tussen jou en die gemeente, of tussen jou en die teks en die God van die teks staan nie. Op geen manier mag jy leef bloot volgens die verwagting, die beeld wat ander van jou het, en jouself so vermom nie. Die waarheid het immers 'n manier om op die duur agter elke vermomming uit te kom.

Feit is: wanneer daar eers ' $n$ inkongruensie tussen jou persoonlike en jou publieke persona ontstaan het, is die skrif aan die muur vir jou prediking. In die prediking kom jou eie hart in die gedrang; word jou eie lewe op die spel geplaas. Predikers moet tuis wees in die huis van hulle eie prediking. As jy bloot 'n huurder is, blyk dit gou (Thielicke 1965:14). Nee, ons mag nooit homiletiese huis-huurders word nie, maar eerder tentbewoners, soos Christus wat onder ons kom tent opslaan het (Joh. 1:14)!

'n Preek is nie bloot iets geleerds wat jy aan ander oordra nie, maar iets wat jy graag self wil sê, omdat jy nie anders kán as om daarvan te getuig nie - soos die titel van 'n ander bekende homiletiekboek onderstreep: The witness of preaching (Long 1989). Ons word geroep om getroue getuies te wees, mense wat self 'n voorbeeld is van een wat (eerste) aangespreek is, geraak is, gekwes is, gebreek is, vertroos is deur die teks, ja, deur die God van die teks. Ons is reisigers in die woestyn wat skuilgaan in die tent van die teks, ja, van Christus - en in die prediking na ander wink om saam met ons in die skadu lafenis te vind.

Wie nie die kamers en gange, die hoeke en draaie van die huis van die teks — of die flappe en hoekpenne van die tent! — ken nie, wie nog nie op en af daardeur of daarom gestap het en daarmee vertroud geraak het nie, kan nie ander innooi en verwag dat hulle sy of haar woord daaroor moet glo nie. Wie byvoorbeeld nie saam met die God van Psalm 130 'n draai in die dieptes gemaak het nie, moet nie oorhaastig op die kansel klim met 'n boodskap daaroor nie; wie nie al die stuwing van lofsegging in elke weefsel van sy of haar bestaan ervaar het nie, moet stadig wees om groot woorde oor Psalm 150 op die kansel uit te spreek.

Ons sou bogenoemde ook vanuit 'n ander hoek kon sê: jy as prediker staan in sekere verhoudings wat juis bepalend is vir jou as prediker, byvoorbeeld jou verhouding tot God (wat jou roepingsbesef insluit), jou verhouding tot jouself (wat dinge soos jou persoonlikheid, psigiese geskiedenis, 
psigiese gesondheid, ens. betrek) en ook jou verhoudings tot ander mense, in die besonder tot hulle vir wie jy wil preek. Wie nie verhoudingsintegriteit het nie, mag wel soos 'n engel praat, maar sal beswaarlik, toegang tot die harte van mense verkry. As jy byvoorbeeld mense nie liefhet nie, het jy geen reg om vir hulle te preek nie (vgl. Jabusch 1981:51-63).

Daar word dikwels juis in dié verband van die spiritualiteit van die prediker gepraat. Dit ís inderdaad van groot belang vir die prediking. Alhoewel ek huiwerig sou wees om te sê dat alles in die prediking daarmee staan of val, of dat my persoon of spiritualiteit as prediker die deurslaggewende verskil is, moet ons die invloed daarvan nie onderskat nie. Onder spiritualiteit verstaan ek: die totale lewe van die predikant, met al die verhoudings waarin so 'n mens staan, onder die gesigspunt van sy of haar roeping om met God te wandel deur die Gees (Gal. 5:16,25).

Die vraag na die spiritualiteit van die prediker — ek verkies die uitdrukking "lewe voor God" - is nie net van teologiese belang nie, maar ook relevant vanuit kommunikasiewetenskaplike oorweginge. Jy kan nie medemense raak as jy nie self (mede)menslik is nie; jy kan nie met passie en integriteit oor God praat as jy nie passie en integriteit hét nie. Die unieke stem van die prediker bring menslikheid in die hele preekmaakproses in, open moontlikhede vir assosiasie en identifisering. Of, teologies gesê: die menslikheid van die prediker gee hande en voete aan die charisma wat deur die Gees van Christus in die lewe van die prediker uitgestort word. Predikers is nié bloot steriele, bloedlose "kanale" waardeur die evangelie tot ons kom nie: die evangelie kom na ons in mensemond en mensewoord anders sou dit nie ons mense-ore en menseharte kon haal nie. Thomas Troeger praat van "the landscapes of the heart" wat in die prediking verruim moet word, dit wil sê die unieke (psigologiese, sosiologiese, ekonomiese, ens.) interpretatiewe raamwerke waarbinne ons almal leef. Om te preek, is om aanhaakpunte te vind by die spesifieke stories, simbole, waardes en rituele wat betekenis aan mense se bestaan gee, om op 'n verbeeldingryke wyse hierdie landskappe van die hart te betree en met die evangelie te verruim. Dít kan jy beswaarlik doen, sê Troeger, as jy nie sélf die landskappe van jou éie hart verken het nie (1999:85-95).

\subsection{Wie nie bid nie, kan nie preek nie}

Wie oor die lewe van die prediker voor God (spiritualiteit) wil praat, kan natuurlik verskillende weë opgaan. Ek verwys slegs na een dimensie, wat na my mening egter grondliggend is: gebed. Dis jammer dat gebed so dikwels gesien word as iets wat los van die teologie staan. Trouens, vir baie is die wêreld van die teologie en die wêreld van gebed prinsipieel — of dan ten 
minste in die praktyk - twee totaal uiteenlopende wêrelde. Dis na my mening 'n fatale skeiding. Ons moet eerder sê: teologie is primêr gebed, en gebed is primêr teologie (vgl. Saliers 1994:15). Net so is prediking primêr gebed; dit kan op géén manier daarvan losgemaak en -gedink word nie (vgl. B.A. Müller 1961:334).

Dis opvallend hoe weinig homiletiekboeke gebed as prinsipiële uitgangspunt neem. Maar, kán ons anders? Spiritualiteit is immers iets wat voortvloei uit jou persoonlike, deurlopende gesprek met God, uit jou eie gebedsbestaan. Gebed stempel jou spiritualiteit, wat weer jou prediking beïnvloed. Preke kan nie sonder gebed "gemaak" word nie. Gebed moduleer jou preekstem.

In die gebed kom onder andere ook die persoon van die prediker soos op min ander plekke aan die orde. Al die menslike ervarings word ingebring wat nog om verwerking roep: die weerstand wat jy van die Bybelteks ervaar, die versperrings tussen jou en die gemeente, jou lewensvrae en -vreugdes. Eugene Peterson skryf:

Prayer is the most deeply human action in which we can engage. Behavior we have in common with the animals. Thinking we have in common with the angels. But prayer - the attentiveness and responsiveness of the human being before God — this is human (1992:111).

In die gebed word die vrae van ons menslike bestaan na God toe opgehou, in die hoop dat daar lig kom wat jy met die gemeente mag deel.

In 'n sin sou ons kón sê dat gebed die geheim van die prediking is. Dis 'n opmerking wat egter vatbaar is vir misverstand. Jy kan redeneer: as ek net bid, is alles in die prediking reg. Jy kan gebed verander in 'n alibi vir eksegetiese luiheid of homiletiese slordigheid. Jy kan onder die wanindruk kom dat die moralistiese hou van "stiltetyd" - teenoor 'n lewenswyse van gebed - 'n waterdigte waarborg vir geslaagde prediking bied. Jy kan gebed probeer inspan as 'n doen-dit-jouself-tegniek om 'n preek aanmekaar te sit. Maar dit is gebed níe. Dit bly 'n gawe van God, wat Hy telkens só aan ons moet gee, só deur sy Gees in ons moet uitstort, dat ons opnuut deur die mond van Christus kan bid (Calvyn; vgl. ook Barth 1969:16-21)

Om 'n Christen te wees, en om te bid, is dieselfde ding (Luther). Om 'n prediker te wees en te bid, is ook dieselfde ding. Gebed bly die grondvorm, die dieptestruktuur van alle prediking (Bohren 1971:104-105). Van Augustinus kom die bekende woord — wat gerus maar op predikers se kansels en studeertafels as lewenspreuk opgeplak kan word: sit orator antequam dictor (eers bid, dan praat). Hy laat hom ook as volg hieroor uit: 


\begin{abstract}
Wanneer die oomblik om te praat aangebreek het, laat hom (die prediker), voordat hy praat, sy dorstende siel na God ophef, sodat hy kan uitdeel wat hy self ingedrink het, self kan uitgiet wat hy opgeneem het... En wie kan maak dat deur ons gesê word wat behoort en soos dit hoort, as alleen Hy in wie se hand ons én ons preke is? (vry vertaal; vgl. Van Oort 1989:18; ook 1991:26).
\end{abstract}

Vir Augustinus bly die prediking 'n gawe van die Gees, 'n goeie woord, 'n goeie preek (sermo bonus) wat die Gees self in die mond van die prediker moet gee - onder andere ook as antwoord op gebed; nee, as verwoording van die gebed. Preke het gebed nie net nodig nie; in 'n sekere sin ís dit gebed. Preke is die soeke om te vind; die klop dat God moet oopmaak — God wat brood gee, en nie 'n klip nie (vgl Mat. 7:7-11). Kortom: Wie nie bid nie, kan nie preek nie. Nie wérklik nie.

In die biblioteek van die Candler Theological Seminary (Emory University, Atlanta) staan daar 'n interessante meubelstuk. 'n Metaalplaatjie verduidelik die geheim daarvan:

Prayer desk or pulpit made for John Wesley about 1740, used by him in preaching to the miners of Wales.

Daar is 'n plek waar Wesley kon staan om te preek, maar ook 'n reling waar hy kon kniel om te bid. Dís hoe ons preekstoele behoort te lyk. Ons preekstoele moet ook bidstoele wees (vgl. Bugg 1992:16).

\title{
2.4 Die deugdelike bestaan van die prediker
}

In 'n sin is dit belangriker wie ons ís as wat ons sê. Daar is 'n filosofiese spreuk wat lui: agere sequitur esse — 'n mens se aksies vloei voort uit jou wese; wat jy doen (en sê) volg uit wat jy ís. Dis ook opvallend dat Paulus, as hy aan Timoteus skrywe om hom aan sy preektaak te herinner, dit eers voorafgaan met 'n verwysing na die deugdelike bestaan van "die man wat in diens van God staan, volkome voorberei en toegerus... vir elke goeie werk" en dan eers kom met die oproep "Ek beveel jou... verkondig die woord..." (2 Tim. 3:17-4:2). Deug, integriteit, egtheid vorm blykbaar die bedding waarbinne die ware kommunikasievermoë vir die prediking gebore word. Wie nie in die klein, alledaagse dinge met integriteit kan handel nie, moet nie dink dat hulle die groter dinge van die Koninkryk met integriteit kan aanpak nie. Die klein gebare van integriteit kommunikeer lank voordat jy al jou preekgebare op die kansel uitvoer. Stanley Hauerwas skryf:

The way we learn a story, after all, is not just by hearing it. Important and significant stories must be acted out. We must be taught the gestures that help position our bodies and our souls to 
be able to rightly hear and then retell the story... the way we learn the story is by learning such gestures as simple as how to kneel (1985:188).

Inderdaad: Lex orandi, lex credendi, lex vivendi, lex praedicandi. Soos jy bid, so bely jy, so leef jy, so preek jy.

Ons moet eers as predikers gemáák word, voordat ons hoegenaamd daaraan kan dink om preke te probeer "maak". Luther het aangrypend hieroor geskryf. Volgens hom is daar drie dinge wat 'n prediker máák, drie basiese elemente in die opvoedingsproses van die prediker as prediker, naamlik gebed, meditasie en beproewing (oratio, meditatio, tentatio). Ongelukkig laat die ruimte nie toe dat hier breedvoerig op elkeen ingegaan kan word nie. 'n Mens sou inderdaad 'n hele homiletiek hieromheen kon ontwerp!

Dit alles wil sê: prediking is nie 'n stokperdjie nie, nie 'n blote kerklike aktiwiteit wat jy net maar "professioneel" kan afhandel nie. Dis 'n lewenswyse. 'n Leerskool. Dit gaan deur jou murg en bloed. Jy preek nie bloot nie. Jy ís 'n prediker. Of nie.

Prediking is verborge ekstase: daaragter lê 'n aangegryp wees deur God. Sê iemand dit mooier as Miskotte?

De preek is een afgekoelde extase, een gestolde verrukking, maar als daar niet dat tongenspreken achter zit, als daar niet het een of ander in de biografie van de man die het doet, of in de gemeente waar het geschiedt, achter zit, van deze verrukking der evidentie, der zekerheid, dan is het toch niet wat de Geest bedoelt (1971: 257,259 - in 'n preek oor 1 Kor. 14:15,20).

Inderdaad: Wie nie die verrukking van die evangelie ervaar nie, word nooit mondig nie.

\section{BIBLIOGRAFIE}

\section{BARTH K}

1969. Prayer and preaching. London: SCM Press Ltd.

BOHREN R

1971. Predigtlehre. München: Kaiser.

1988. Das Ich in der Predigt. Konsequenzen für den Lektorendienst. Das missionarische Wort 3(88):98-107. 
Cilliers

Die geheim van die prediking

BROOKS P

1964. On preaching. New York: Seabury.

BUGG C B

1992. Preaching from the inside out. Nashville: Broadman Press.

DEN DULK M

1995. De homiletiek van C.J.A. Vos. Praktiese Teologie in Suid-Afrika 10(1): 6-14.

DingEMANNS G D J

1991. Als hoorder onder de boorders... Een hermeneutische homiletiek. Kampen: J.H. Kok.

HAUERWAS S

1985. The gesture of a truthful story. Theology Today 42:181-189.

IWAND H J

1964. Gesetz und Evangelium. Nachgelassene Werke 4. München: Kaiser.

JABUSCH W F

1981. The person in the pulpit. Preaching as caring. Nashville: Abingdon Press.

LONG T G

1989. The witness of preaching. Westminster: John Knox.

MEUSER F W (Ed)

1969. Interpreting Luther's legacy. Minneapolis: Augsburg.

MisKotTe K H

1971. Om de waarbeid te zeggen. Kampen: J.H. Kok.

MÜLlER B A

1961. Die lewende Woord aan die mens van die hede. 'n Bespreking van die vrae rondom die aktuele Woordverkondiging. Zaandijk: J. Heijnis Tsz.

NeL $M$

2000. Persoonlike prediking. Praktiese Teologie in Suid-Afrika 15(2):112-135.

2001. Ek is die verskil. Die invloed van persoonlikheid in die prediking. Bloemfontein: C.L.F. Uitgewers.

Peterson E H

1992. Under the unpredictable plant. An exploration in vocational holiness. Grand Rapids, Michigan: Eerdmans.

Pieterse H J C

1988. Die Woord in die werklikheid. ' $n$ Teologie van die prediking. Pretoria: N.G. Kerkboekhandel.

2002. Prediking in 'n postmoderne lewensgevoel. Praktiese Teologie in Suid-Afrika 17(1):76-96.

\section{SALIERS D}

1994. Worship as theology. Foretaste of glory divine. Nashville: Abingdon. 


\section{THIELICKE $\mathrm{H}$}

1965. Leiden an der Kirche. Ein persönliches Wort. Hamburg: Furche-Verlag.

\section{Troeger T H}

1999. The landscapes of the heart. How our imagined worlds shape the preaching of the gospel. In: Preaching as God's Mission. Studia Homiletica 2 (Tokyo: Kyo Bun Kwam), 85-95.

VAN MELLE J

1968. Bart Nel. Pretoria: J.L. van Schaik.

\section{VAN OORT J}

1989. Augustinus. Facetten van leven en werk. Kampen: Kok.

\section{VAN OORT J}

1991. Bediening van het heil. Augustinus over de prediking. Leiden: Uitgeverij J.J. Groen en Zoon.

\section{Vos C J A}

1995. Die Blye Tyding. Homiletiek uit 'n hermeneuties-kommunikatiewe perspektief. Pretoria: RGN.

WARD R F

1992. Speaking from the heart. Preaching with passion. Nashville: Abingdon Press.

WILSON P S

1995. The practice of preaching. Nashville: Abingdon.

Trefwoorde

Homiletiek

Persoonlikheid

Spiritualiteit

Gebed

Etos
Keywords

Homiletics

Personality

Sprituality

Prayer

Ethos 